\title{
Development of Reverse Logistics in the Tourist Industry as a Factor of Sustainability of Territory Development
}

\author{
Olga Pliska, Elena Ivlieva*, Irina Sofronova
}

\author{
Ural State University of Economics, Ekaterinburg, Russia \\ *Corresponding author.Email: eaivlieva@mail.ru
}

\begin{abstract}
The paper considers the issue of stable tourist industry. In this respect the authors define and analyze provisions of reverse logistics in this sphere. Analysis method is used to construct logic scheme and quantify generic feature, generic concept, form of functioning of content and system quality of reproduction of reverse flows. Two groups of consumers of services in tourism are identified: tour consumers and tour collectors. RFR statistics for these two groups are described with the following indices: index of supply of means of production, index of goodwill of tourists, index of the financial burden of tourists and index of the contribution of tourists to economic growth. The authors stress the idea that reduction of the second group negatively affects the sustainable development of the territories
\end{abstract}

Keywords: reverse logistics, reverse flow reproduction, increasing/diminishing marginal utility, a package tour.

\section{INTRODUCTION}

In terms of sustainability (unlimited long-term functioning) reverse logistics can be considered in the following ways: 1) rarity of variety of types of creativity, 2) a digital space that introduces specifics into the ways of limiting rarity, 3) a result of the synthesis of knowledge of increasing utility, 4) a system quality excluding some phenomena from the law of diminishing marginal utility.

In the first case, the modern world is perceived as a monetary world. The informative value of the price signal for consumers reflects the idea of usefulness of goods and services. The supply-demand ratio for services of the tourist industry, reflected in the price, is an indicator of value. And the latter, in turn, is determined by a combination of desires and difficulties of satisfying them (rarity) [1]. We can say that rarity is correlation between the services given and the ones that could be used. Thus, in numerous studies the value is determined not only by the internal properties of things and their ability to meet human needs, but also by the fact how many consumers can afford this service [2]. Thus, reverse logistics, including many types of creative principles and craft components (decorative-applied, fine arts, performing, etc.), is objectively 'tied' to rarity since aesthetics here is inseparable from the man-made material form.
A different approach is contained in the works showing that modern digital space introduces specifics in the ways of restricting access to rare manifestations [3]. Indeed, once created, digital products turn into inexhaustible and uncompetitive goods to be consumed, which is why they can be sold at the lowest price. Therefore, at any level of consumption, it costs almost nothing for the manufacturer to serve an additional customer.

It is necessary to pay attention to the fact that recently there have been works on reverse logistics, in which there is a synthesis of scientific knowledge about increasing utility $[4,5]$. In terms of all the elements of value (cultural value included), their material basis (content) is taken into account within the framework of the theory of utility. Guided by personal cultural criteria, consumers of tourist services determine the priority of aesthetic, spiritual and other values of a certain object - a package tour. The difference in the willingness to pay (or the willingness to consume in large quantities) can be interpreted as a measure of differences in cultural value. It should be noted that in the digital segment, the consumer may be ready to pay more for the best, but according to market conditions, it is not required: there is no correlation between the price and the value system, the question of the order of formation of consumer preferences is not raised. As a result, the difference in utilitarian and cultural needs is overlooked. The former ones act automatically, but the 
latter do not. For example, food markets in tourist destinations do not need to study the biochemistry of food. The consumer simply cannot give up food. However, the demand for cultural services does not arise automatically, and it is heterogeneous. Thus, physiological needs vary widely depending on the way of life, and "optional" cultural requests depend on cultural and social norms. Thus, the study of the aspects of price and values for reverse logistics as a form of functioning in the markets of digital products and in the field of material aesthetics (luxury and taste industry) makes it possible to determine certain flows based on the results of tourists presence in recreation areas [7].

Finally, from the standpoint of systemic quality, a number of works claim that collecting, tour collection included, is an exception to the law of diminishing marginal utility [6]. However, the problem of noncompliance with the basic market principles can be considered in terms of a tour as a unit of measurement of the entire "collection" and in terms of its individual elements. Indeed, in the second case, the law of diminishing marginal utility comes into force: the incompleteness of "tour collecting" is not an exception, but a rule, and not only in "collecting", but in general in consumption. Moreover, the idea of "tour collecting" may change, as well as a person's self-consciousness. Therefore, each collector's purchase, as a result of reverse logistics, complements the existing set, but does not end it. The value that the new component adds to the tourist product may not correspond at all to the value (price) of the newly acquired service [7].

\section{MATERIALS AND METHODS}

Formalizing reverse logistics, or, as we define it, reverse flow reproduction (RFR), involves analyzing its economic essence, the core of which is deals between producers, suppliers and consumers of tourist products. The dual behavior of consumers of tourist products is characterized not by their abstract preferences and desires, but by the desire to acquire specific values in order to create conditions for self-realization. To build a logical scheme [8] and justify the use of the RFR toolkit, we use the analysis method based on defining and quantitative assessing its generic feature, generic concept, functioning of the content and system quality for the main groups of consumers of tourist services.

The concept of reproduction of return flows for producers, suppliers and consumers of tourist services is understood as" the supply of means of production..., which occurs as a starting point in many recurring periods of production", which gives grounds to define this "nest of concepts" as a generic feature of RFR, namely, as "supply of means of production as a special sphere of production" [9]. In the logistics chain, the following characteristics of consumers in the tourist sector can be determined. The first is the growing volume of needs leading to the rapid emergence of new utilities that are multiplied in the minds of tourists. The second feature is determined by the conditions for meeting the ever-increasing needs of tourists keeping cultural values. It is characterized by their economic opportunities. Thus, the description, as well as the quantitative assessment of the RFR can be represented by the index of supply of means of production, which includes firstly, the final results created by tourists due to new utilities, and, secondly, the labor resources that provide this result. In other words, to calculate this index, the gross value added is compared with the export of services (under the travel item).

Further, systematization of knowledge about RFR involves description not only of its generic feature, but also its generic concept. In this regard, for a number of researchers [10], it includes a variety of essential features of transforming economic status of tourists (either aimed only at the consumption of a tourist product, or at consumer behavior of "collecting" tours). The status under consideration is realized as a result of the use of disposable income not for any purchases, but only for those that serve as RFR and are perceived as goodwill, i.e. the good name of the tourist [11]. The quantitative assessment based on the corresponding goodwill index of tourists is associated with determining changes in the value of value added and the result of investment in fixed assets.

The next element that researchers pay attention to when systematizing the knowledge of reverse logistics and can be used in determining RFR is the description of its material basis [12]. In this case, the content of RFR can be interpreted as an investment, i.e. "capital investments aimed at providing the enterprise" [13]. The specifics of this study, namely the service sector, seems to confirm that the material basis (content) of RFR is not so much the quantity and quality of capital expenditures (investments), but tourist self-development or desire to preserve certain types of activities as a result of the lack of cash-back or other financial support tools. We think that the main purpose of financing RFR is to provide tourists with the necessary monetary resources to be used in capital transactions to create new utilities as a reaction to existing problems of manufacturers and suppliers of tourist products. The form of functioning of the material basis of RFR "is that the result of the tour by each individual tourist in accordance with the tourist product offered is manifested in the ability to satisfy the needs of contractors by manufacturers and suppliers. It is observed in the growth rates of entrepreneurial actions of consumers having different abilities with limited profit growth rates. The formula for the price of a tourist-consumer can be determined, for example, by the number of subscribers in social networks and is formed by the specified proportions of the market segment [14]. Therefore, it is absolutely wrong to say that the price of RFR for a tourist-consumer mainly depends on the growth rate of manufacturers and suppliers of tourist services. A rationally acting consumer obeys the set proportions of RFR and, consequently, the 
growth rates are set to him objectively by the entire system of participants in the tourist industry [15]. Therefore, when quantifying the process under consideration and calculating the financial burden index, it is necessary to take into account the ratio of GVA and the volume of paid services.

The last element of the methodology under consideration contains a description of the system quality of reverse logistics, which is considered in publications as an approach aimed at setting and solving problems concerning the personnel of manufacturers and suppliers of package tours. Moreover, scientists note that when considering the system quality, personnel should be considered regardless of their functional area [16]. In our opinion, the most adequate feature of the interaction of the generic concept, content and form in relation to RFR is its systemic quality, which ensures the status of tourists who are able, on the one hand, to develop the economic system, on the other, to preserve the activities of intermediaries. In this regard, the quantitative feature of the system quality is the contribution of tourism to the national economy due to reverse logistics. Thus, the index of the contribution of tourists to the economy is determined by the ratio of the number of employees in tourist companies and the number of people in collective accommodation facilities.

\section{RESULTS AND DISCUSSION}

The study identified two groups of consumers of services in tourism - a group aimed directly at the consumption of tourist services, i.e. "net consumers" on the one hand, and "additional consumption" group, the socalled group of "collectors", on the other. The second group is characterized by the fact that the replenishment of "tour collection" usually has an increasing value, which to a certain extent contradicts the postulates of economic theory concerning marginal utility. In this regard, the assessment of RFR among net consumers of tourist services, on the one hand, and collectors, on the other, is of particular importance. Indirectly, such an assessment can be carried out on the basis of comparing the indicators of entrepreneurial activities of the population in the Russian Federation in recent years. According to the National Report "Global Monitoring of Entrepreneurship, Russia 2019-2020" [17] in 2016, the total entrepreneurial activity was $11.3 \%$ as for the working-age population of the country in the Russian Federation (84.20 million people), and by $2019-14.4 \%$ as for the working-age population of the country ( 81.36 million people). It can be assumed that the values of entrepreneurial activity and creativity when collecting tours are correlated to a certain extent. In this case, in 2016, the share of net consumers was almost 35 million people, and the share of collectors was about 10 million people, the citizens of the Russian Federation placed in collective accommodation facilities $(48,338,704$ people) included. In 2019, the share of net consumers was about 47.5 million people, and the share of collectors was about 12 million people, the citizens of the Russian Federation placed in collective accommodation facilities $(65,185,770$ people $)$ included.

RFR statistics for these two groups can be described by the following indices: the index of supply of means of production, the index of goodwill of tourists, the index of the financial burden of tourists and the index of the contribution of tourists to economic growth. The data necessary for calculating the indices are presented in tables 1-4. [18]

The economic meaning of the index of supply of means of production is that a certain amount of newly added value in the tourist industry accounts for one monetary unit of export of services annually. For example, in 2011, the production index was 135.66. After that it was constantly growing, with the exception of 2018, when the drop was $16.4 \%$.

The calculation data show that the goodwill index is characterized by significant fluctuations. During the nineyear period, investments in fixed assets fell in 2013 and grew significantly in 2015, which affected the ratio of the cost of GVA and the cost of investments in fixed assets: so, in 2013 , the index decreased by $47.2 \%$, and in 2015 it increased by $38.17 \%$.

The table shows that the absolute indicators of the volume of paid services and GVA in comparison with the indicators of the financial burden index have approximately the same trend over the years, the increase in the financial burden index having a directly proportional dependence during all the years, with the exception of 2013, 2015 and 2019.

The index of contribution of tourists to the growth of the economy shows that since 2015 the load on one employee in a travel company slightly decreased which indicates an increasing trend of replacing variable capital

Table 1. Determination of the index of supply of means of production in 2011-2019

\begin{tabular}{|l|c|c|c|c|c|c|c|c|c|}
\hline Periods & 2011 & 2012 & 2013 & 2014 & 2015 & 2016 & 2017 & 2018 & 2019 \\
\hline $\begin{array}{l}\text { Provided services(tours) } \\
\text { bln. rub. }\end{array}$ & 11,3 & 10,8 & 12,0 & 11,8 & 8,40 & 7,80 & 8,90 & 11,6 & 11,0 \\
\hline GVA bln. Rub. & 1533,1 & 1778,1 & 2052,4 & 2300,9 & 2444,3 & 2610,5 & 3270,7 & 3661,5 & 3817,5 \\
\hline $\begin{array}{l}\text { Production index=GVA/providing } \\
\text { services }\end{array}$ & 135,66 & 164,63 & 171,03 & 194,99 & 290,98 & 334,67 & 367,49 & 315,64 & 347,04 \\
\hline
\end{tabular}


Table 2. Determination of the goodwill index of tourists in 2011-2019

\begin{tabular}{|l|c|c|c|c|c|c|c|c|c|}
\hline Periods & 2011 & 2012 & 2013 & 2014 & 2015 & 2016 & 2017 & 2018 & 2019 \\
\hline $\begin{array}{l}\text { Investments in fixed } \\
\text { assets, mln. Rub. }\end{array}$ & 41223,7 & 27632,0 & 67449,0 & 80468,0 & 32635,0 & 30366,0 & 323483,4 & 42861,1 & 36683,0 \\
\hline GVA,billion rub. & 1533,1 & 1778,1 & 2052,4 & 2300,9 & 2444,3 & 2610,5 & 3270,7 & 3661,5 & 3817,5 \\
\hline $\begin{array}{l}\text { Goodwill } \\
\begin{array}{l}\text { index=GVA/investments } \\
\text { in fixed assets }\end{array}\end{array}$ & 37,18 & 64,34 & 30,42 & 28,59 & 74,89 & 85,96 & 100,68 & 85,42 & 104,06 \\
\hline
\end{tabular}

Table 3. Determination of the financial burden index in 2011-2019

\begin{tabular}{|l|c|c|c|c|c|c|c|c|c|}
\hline Periods & 2011 & 2012 & 2013 & 2014 & 2015 & 2016 & 2017 & 2018 & 2019 \\
\hline $\begin{array}{l}\text { Paid services, } \\
\text { bln. rub. }\end{array}$ & 112,8 & 121,6 & 143,8 & 147,5 & 158,3 & 161,3 & 166,5 & 172,1 & 179,8 \\
\hline GVA, bln. rub. & 1533,1 & 1778,1 & 2052,4 & 2300,9 & 2444,3 & 2610,5 & 3270,7 & 3661,5 & 3817,5 \\
\hline $\begin{array}{l}\text { Financial burden } \\
\text { index=GVA/paid } \\
\text { services }\end{array}$ & 13,59 & 14,62 & 14,27 & 15,59 & 15,44 & 16,18 & 19,64 & 21,27 & 21,23 \\
\hline
\end{tabular}

Table 4. Determination of the index of the contribution of tourists to the economy in 2011-2019

\begin{tabular}{|l|c|c|c|c|c|c|c|c|c|}
\hline Periods & 2011 & 2012 & 2013 & 2014 & 2015 & 2016 & 2017 & 2018 & 2019 \\
\hline $\begin{array}{l}\text { Tourists } \\
\text { accommodated } \\
\text { collectively, } \\
\text { mln people }\end{array}$ & 33,18 & 36,01 & 37,0 & 38,4 & 49,28 & 54,43 & 61,56 & 71,53 & 76,0 \\
\hline $\begin{array}{l}\text { The number of } \\
\text { employees in travel } \\
\text { companies, thousand } \\
\text { people }\end{array}$ & 47,5 & 48,7 & 50,1 & 45,5 & 48,4 & 40,0 & 47,2 & 66,7 & 61,3 \\
\hline $\begin{array}{l}\text { Index of contribution } \\
\text { of tourists to the } \\
\text { economy= number } \\
\text { of } \\
\text { employees/number } \\
\text { of tourists }\end{array}$ & 0,00143 & 0,00135 & 0,00135 & 0,0011 & 0,00098 & 0,00073 & 0,00076 & 0,00093 & 0,0008 \\
\hline
\end{tabular}

(primarily labor) with fixed capital (for example, telecommunications equipment).

\section{CONCLUSION}

The study analyzes the theoretical foundations of reverse logistics based on four provisions: firstly, rarity of a variety of types of creativity, secondly, a digital space that introduces specifics into the ways of limiting rarity, thirdly, a result of the synthesis of knowledge of increasing utility, fourthly, a system quality excluding some phenomena from the law of diminishing marginal utility. The logic of such a study is proved by conclusions of research in the field of symbolic exchange Collecting in pure form is an exception to the law of diminishing marginal utility. However, the problem of non-compliance with basic market principles can be considered in two ways: if we look at either a tour as a unit of measure of the entire "collection" or individual elements.

Further, in the methodological plan, the characteristics of RFR are determined on the basis of its generic feature, generic concept, functioning of content and systemic quality for the main groups of consumers of tourist services. In terms of individual elements of a tourist product, the law of diminishing marginal utility proves to act: the unfinished "tour collection" is not an exception, but a rule, and not only in "collection," but in general in consumption. A tourist collector seeks to find facts to replenish his collection, while a tourist consumer picks up things to "build" himself. Moreover, the idea of a "tour collection" can change, as well as the self-consciousness of a person. Therefore, each acquisition of the collector, as a result of RFR, complements to the existing set, but does not end it. The value that the new component adds to the tourist product may not correspond at all to the value (price) of the newly acquired product, alone, and, therefore, the process is not subject to the law of diminishing marginal utility.

Thirdly, RFR statistics for these two groups of tourists are described by the following indices: the index of supply of means of production, the index of goodwill of tourists, the index of financial burden of tourists and the index of contribution of tourists to economic growth. The volume of new benefits for tourists aimed at collecting and 
creating RFR due to the export of services (under the travel item) during the study period is generally positive.

Assessing the economic status of tourists contributing to the growth of fixed capital of producers of tourist products, it was revealed that during the observation period the goodwill index fluctuated significantly. On the whole, a favorable climate for RFR was achieved due to the state support.

The financial burden of RFR is determined on the basis of a comparison of indicators of the volume of paid services and the value of the new cost, the increase in indicators characterizing the financial burden index having a directly proportional dependence during all years, with the exception of 2013, 2015 and 2019.

The contribution of the tourist industry to the GDP of the national economy and the volume of RFR can be determined on the basis of a comparison of the number of employees in tourist firms and the number of people accommodated collectively. The data indicate that during the period from 2011 to 2019 there was a slight change in the index of the contribution of tourists to the economy from 0.00143 to 0.0008 .

Overall, the evaluation done for the period 2011-2019 year shows that in the post-pandemic period, risks for RFR are likely to happen as a result of the expectation of attracting significant resources, primarily, for investments in fixed assets.

\section{REFERENCES}

[1] V. G. Kogdenko, M. V. Mel'nik, Modern trends in business analysis: researching the company's ecosystem, analyzing the information component of the business model, assessing growth opportunities, Regional economy: theory and practice, 16(1) (2018) pp. 38-57.

[2] E. V. Nekhoda, N. A. Redchikova, N. A. Tyuleneva, Business models of companies: from profit to sustainable development and value creation, Manager 9(4) (2018) pp. 9-19. DOI: https://doi.org/10.29141/2218-5003-2018-9-4-2.

[3] M. A. Bek, N. N. Bek Business models: innovative aspects, Management of innovations, 4 (2014) pp. 244-256.

[4] N. D. Strekalova, The concept of a business model: methodology of system analysis, Bulletin of the Herzen Russian State Pedagogical University. Science Magazine, 92 (2009) pp. 95-105.

[5] L. Melián-Alzola, M. Fernández-Monroy, M. Hidalgo-Peñate, Hotels in contexts of uncer tainty: Measuring organisational resilience. Tourism Management Perspectives, vol. 36, (2020) 100747. DOI: https://doi.org/10.1016/j.tmp.2020.100747.
[6] V. A. Minaev, L. A. Ul'yanchenko, E. A. Cyshchuk Assessment of tourist resources and the quality of tourism infrastructure in municipalities, Bulletin of the Association of Tourism and Service Universities, 9(3) (2015) pp. 4-13

[7] O. Gassman, K. Frankenberger, M. SHik Biznesmodeli. 55 luchshih shablonov: per. s angl. M.: Al'pina Pablisher, 2019.

[8] G. I. Idrisov, V. A. Mau, A. V. Bozhechkova, In search of a new growth model, Economic Issues, 12 (2017) pp. 1-19.

[9] E. P. Dyatel, Enterprise economy. Tesauras. Publishing house Ur. State Economics University, 2000, pp. 190.

[10] K. Rihter, Some trends in the development of logistics in the market system, Logistics in an interconnected world. Materials of the international scientific-practical conference, Yekaterinburg, 2004, pp. 7-9.

[11] D. G. Praničević, A. Mandić, ICTs in the hospitality industry: An importance-perfor mance analysis among small family-owned hotels. Tourism, 68(2) (2020) pp. 221-234. DOI: https://doi. org/10.37741/t.68.2.9.

[12] M. S. Oborin, M. Yu. SHeresheva, The specifics of network business models in the tourist and recreational sphere, Manager, 4(68) (2017) pp. 24 31.

[13] A. Osterval'der, I. Pin'e, Building business models. Handbook of the strategist and innovator, per. from English M. Kulneva, Alpina Publisher,2013, pp. 69.

[14] N. V. Pahomova, K. K. Rihter, M. A. Vetrova, Transition to a circular economy and closed supply chains as a factor of sustainable development, Bulletin of St. Petersburg University. Economy, 2 (2017) pp. 244-268. DOI: https://doi.org/10.21638/10.21638/11701/spbu05.20 17.203.

[15] A. K. Jha, Tourism in Mithila: Identification of resource potentials and prospects for tourism development. Bilingual Quarterly Research Referral Journal, 7 (2020) pp. 188-206.

[16] A. Dolgih, The economy of symbolic exchange, Infra-M., (2006, pp. 625.

[17] Global Monitoring of Entrepreneurship, Russia 20192020, http://gsom.spbu.ru.

[18] Statistical indicators characterizing the development of the tourism industry in the Russian Federation, http://tourism.gov.ru. 